\title{
SEE Laboratory: Single-Story, Single-Bay Portal Frame
}

\author{
Jessica Opinion, Veronica Rico, Melissa Guardado, David Boyajian and Tadeh Zirakian \\ Department of Civil Engineering and Construction Management, California State University, Northridge, CA 91330-8347, USA
}

\begin{abstract}
This research paper describes an SEE (Structural Engineering Encounter) Lab project. The paper reports on the development of a single-story, single-bay portal frame model as part of the $\mathrm{AIMS}^{2}$ (attract, inspire, mentor and support students) grant supported through the US DOE (Department of Education) summer research program at California State University, Northridge. This research effort is part of a comprehensive program to develop laboratory models of structures commonly encountered in civil engineering practice, which can serve the dual purpose of accomplishing engineering education and research in the areas of structural and earthquake engineering. The objective of the present study was to construct a physical model of the aforementioned frame to experimentally collect data due to the application of vertical and lateral loadings through instrumentation such as strain gages and an LVDT (linear variable differential transformer) displacement transducer, and also to make comparisons with theoretical and numerical predictions.
\end{abstract}

Key words: SEE lab, active learning, portal frame, experimentation, theory, numerical simulation.

\section{Introduction}

Civil engineering involves structures that range from simple buildings and highways to complex bridges and dams. Aspiring civil engineering students are required to learn and encounter structural engineering courses concerned with the study of structural analysis, design and its applications. Many structural engineering courses are lecture and laboratory based in which students must model and analyze structures and perform experiments on models that visually and mechanically represent real life structures and the different forces, strains and stresses that such structures may experience. The laboratory portion of these courses provides a visual aid that is essential to the overall comprehension of engineering students since they are able to encounter and apply basic concepts in structural engineering. Several studies [1-4] show the importance of hands-on learning for engineering students. In these, it was demonstrated that the performance levels of students enrolled in combined lecture and hands-on laboratory courses were enhanced over those enrolled in engineering theory without a

Corresponding author: Tadeh Zirakian, Ph.D., P.E. E-mail: tadeh.zirakian@csun.edu. laboratory component. In addition, small group collaborations were found to have "positive effects on undergraduates in STEM (science, technology, engineering, and mathematics) courses and programs" [5]. Physical models allow students to directly observe behavior of structures in a realistic setting and enables them to realize the discrepancies between idealizations and phenomena occurring in the physical world. According to another study [6], engineers must be able to use their knowledge of theory and be able to effectively apply it in practice, making the case for laboratory based instruction all more essential.

Based on the aforementioned principles in engineering education, the Department of Civil Engineering and Construction Management at California State University, Northridge (CSUN), requires its students to take theoretical and experimental courses in structural mechanics. However, due to the age and disrepair of some equipment along with certain experiments being non-structural in essence as implemented from the past, two newly hired professors, Dr. Boyajian and Dr. Zirakian, envisioned transforming the current laboratory environment to upgrade it to an effective active-learning laboratory experience. This so-dubbed SEE (structural 
engineering encounter) lab is the first step in developing more structure-based, active-learning experiments to demonstrate basic concepts of mechanics to future generations of engineering students.

This effort, made possible through a US DOE grant, i.e., the $\mathrm{AIMS}^{2}$ (attract, inspire, mentor and support students) initiative, included the design, construction, and testing of a single-story, single-bay portal frame model to demonstrate basic principles of structural engineering. The simple frame design was chosen in order to demonstrate applications of a variety of loads and load-paths with different constraints. Basic outcomes to be gained through the use of these experiments aimed at a better understanding of concepts of engineering stresses and strains. To this end, following careful design, construction, instrumentation, and testing of the frame model, explained in greater detail in this paper, the obtained experimental results served to motivate the students to perform theoretical analysis and numerical simulations for purposes of corroboration. The objective of this paper is to provide a template for educators with the aim of promoting an effective engineering education through the development of an active-learning experience.

\section{Details of the Physical Frame Model}

\subsection{Design}

To begin this research endeavor, a single-story, single-bay portal frame was considered. Fig. 1 shows the geometrical dimensions of the frame as well as a view of the cross section of the members used made of acrylic glass. The design of the frame includes a base with adjustable parts that can accommodate different-sized beams and materials.

\subsection{Construction}

The frame was constructed from acrylic glass members and a steel base, supported by aluminum joints as seen in Fig. 2. A pulley system is attached to the frame using a vertical mount where exact weights can be added to apply lateral loading and from which the induced deflection can be measured by means of a LVDT (linear variable differential transformer), as shown in Fig. 3.

\subsection{Instrumentation}

Fig. 4 shows the DAQ (data acquisition) system. This system converts measurements acquired from the strain gages and the LVDT instruments as digital output that can be related to actual deformation

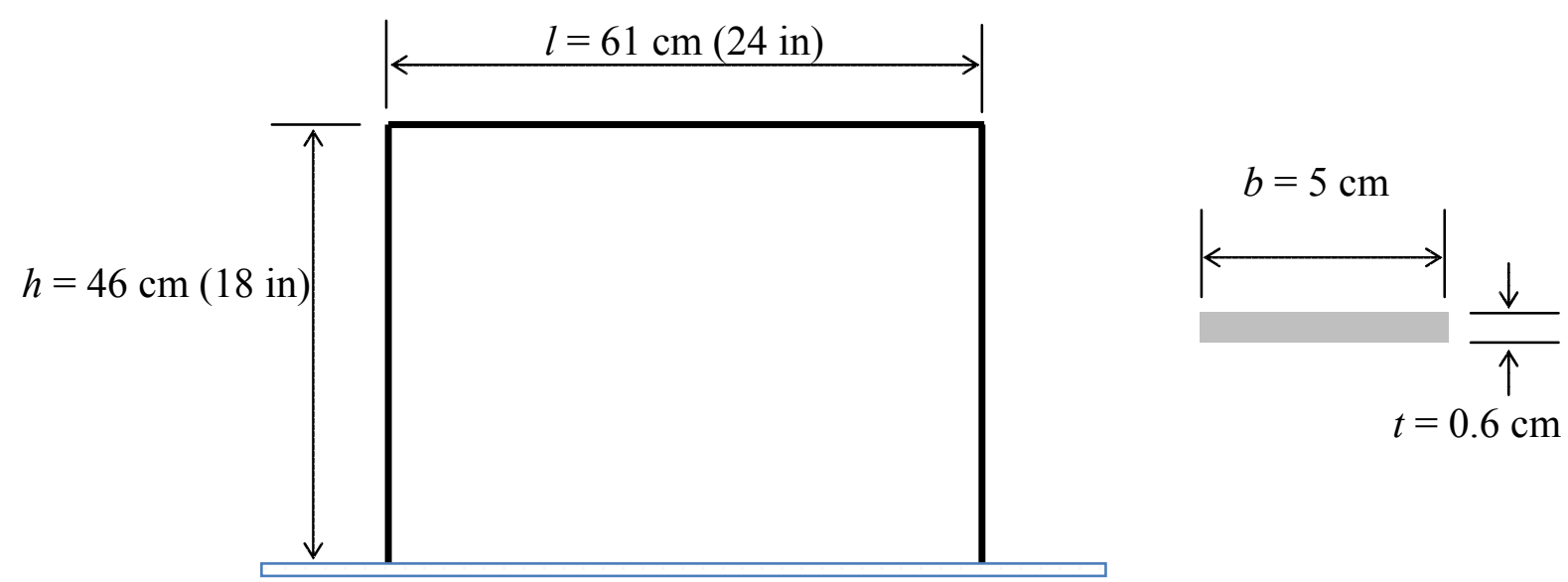

Fig. 1 Schematic of portal frame with cross sectional view. 


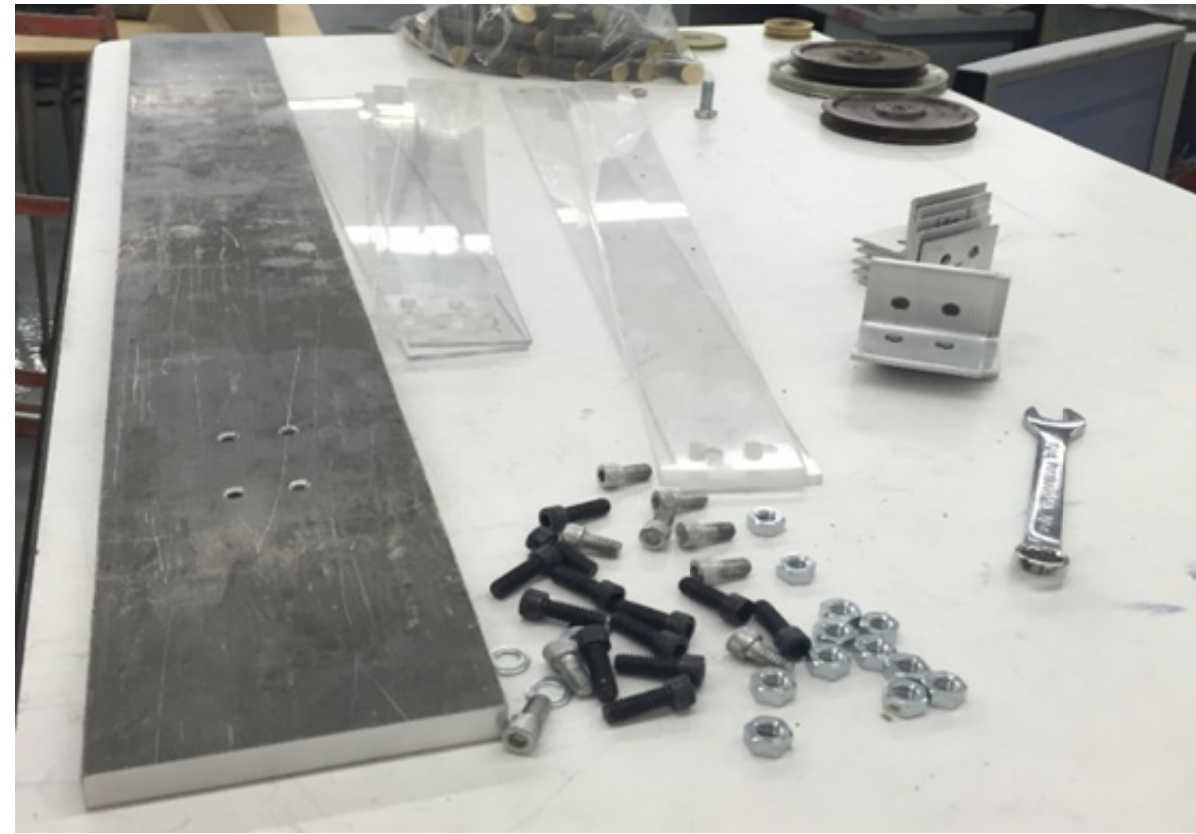

Fig. 2 Materials used in the construction of the single-story, single-bay portal frame.

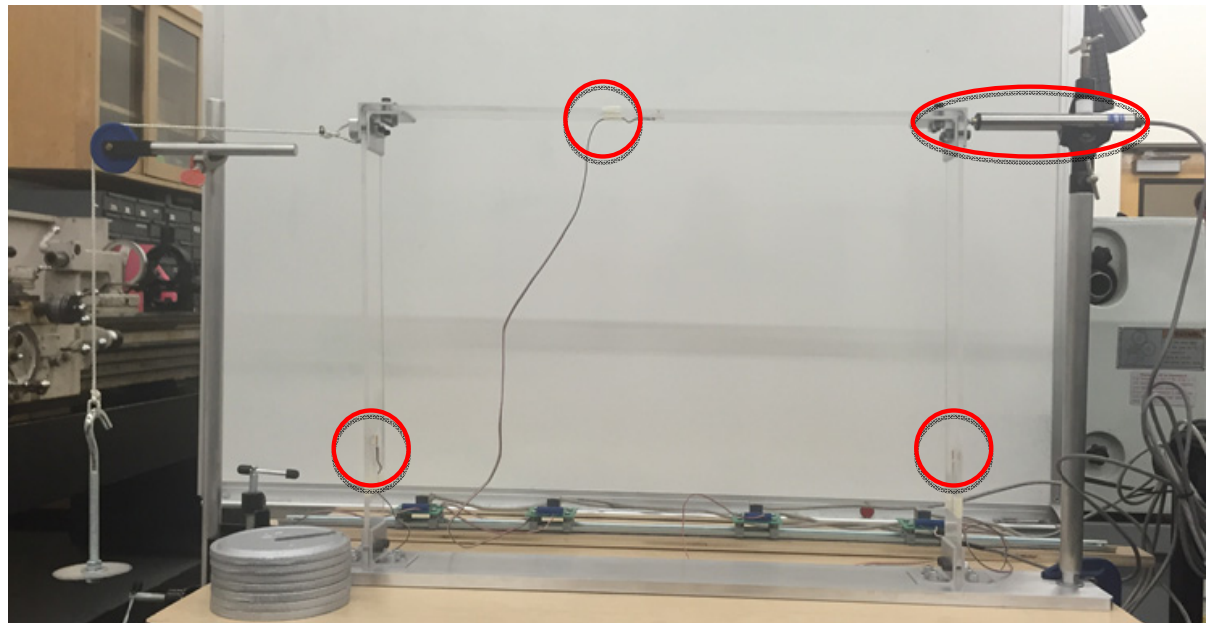

Fig. 3 Overall view of the constructed single-story, single-bay frame with instrumentation.

characteristics, i.e., strain and deflections. It contains four channels, one per gage, and one for the LVDT. The three $350 \mathrm{ohm}$ strain gages used were mounted on both columns and at the midspan of the beam as shown circled in Fig. 3. Using the DAQ system enabled the monitoring and evaluations of the portal frame under both vertical as well as lateral loadings.

An example of the frame being subjected to both vertical (uniformly distributed) and lateral loadings, shown in Fig. 5, together with the DAQ ouput per channel for the three strains and the lateral deflection in $\mathrm{mV} / \mathrm{V}$ which was subsequently calibrated to millimeters.

\subsection{Loading}

The frame can be loaded vertically through the placement of small aluminum cylinders cut in length to match the width of the beam, while lateral loading is achieved through a hanging-weight-pulley system as pictured in Fig. 5.

In order to compare experimental results with numerical and theoretical predictions, a point-load of $7.16 \mathrm{~N}(1.61 \mathrm{lb})$ was applied at the midspan of the beam using 6 uniform brass cylinders stacked one on 


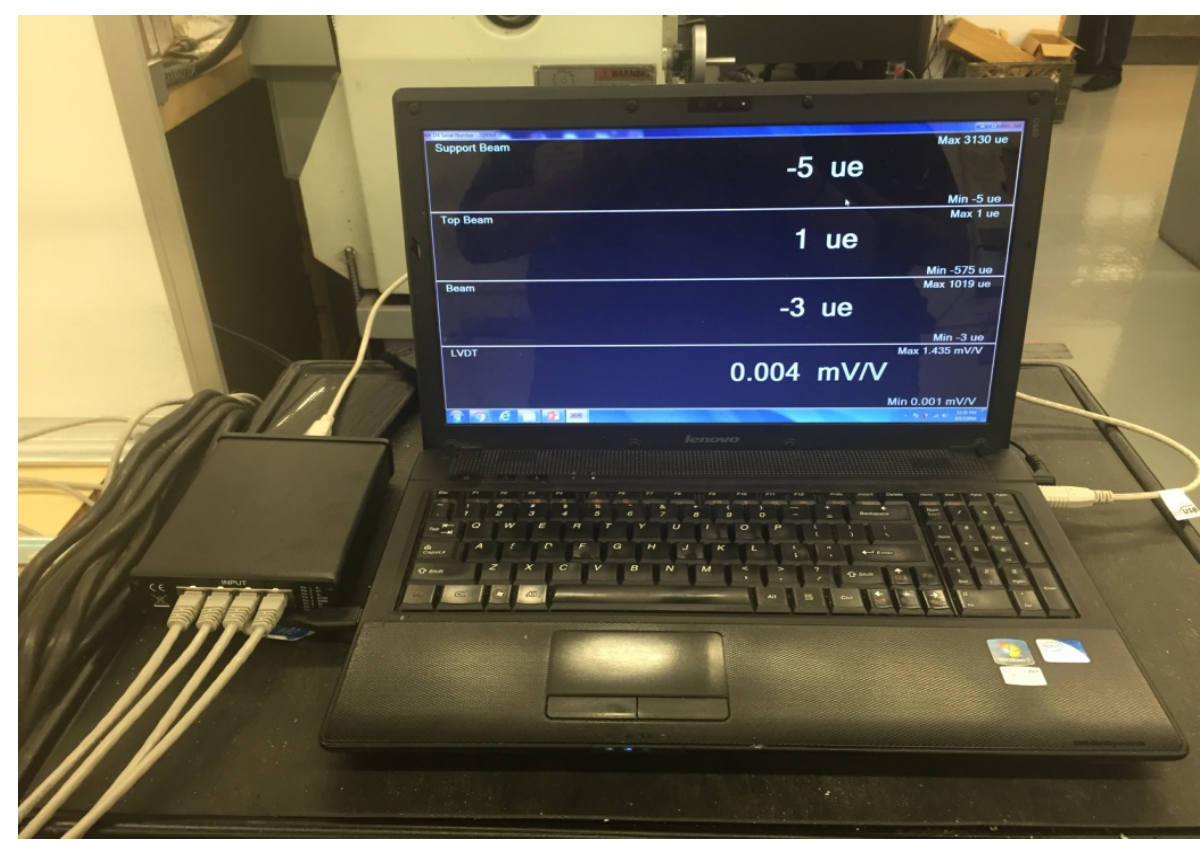

Fig. 4 DAQ system.

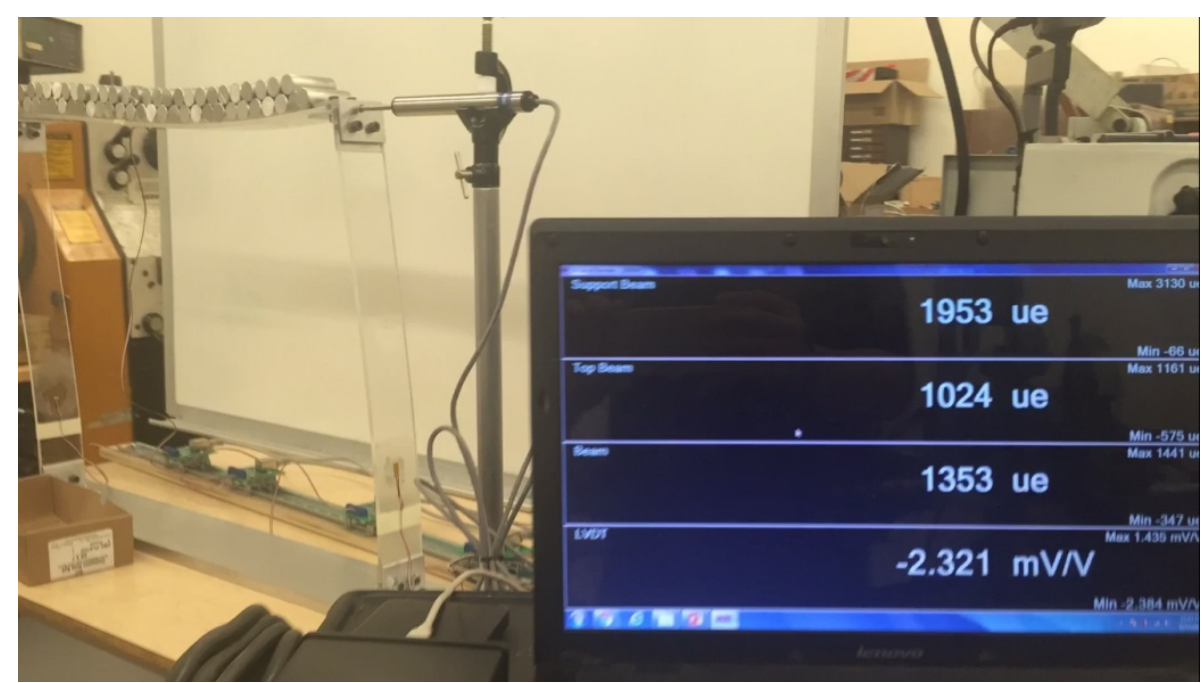

Fig. 5 Strain and deflection readings due to lateral and vertical loadings of the frame.

top of the other, with discussion of the results provided in the following. The LVDT was placed below the beam to measure the physical displacement from the applied point load.

\section{Discussion of Results}

\subsection{Numerical Simulation of the Physical Frame Model}

RISA-2D was used for numerical simulation of the portal frame. As explained before and shown in Fig. 6, a concentrated load of $P=7.16 \mathrm{~N}(1.61 \mathrm{lb})$ was applied at the midspan of the beam. The numerical model was constructed to simulate the actual physical model. The geometrical dimensions of the frame shown in Fig. 1, were used in modeling the frame. In addition, the Young's modulus $(E)$ of the material was taken as 3.1 GPa (450,000 psi).

\subsection{Theoretical Analysis of the Physical Frame Model}

For theoretical calculations, beams with simple and clamped support conditions were considered, as shown in Fig. 7. 


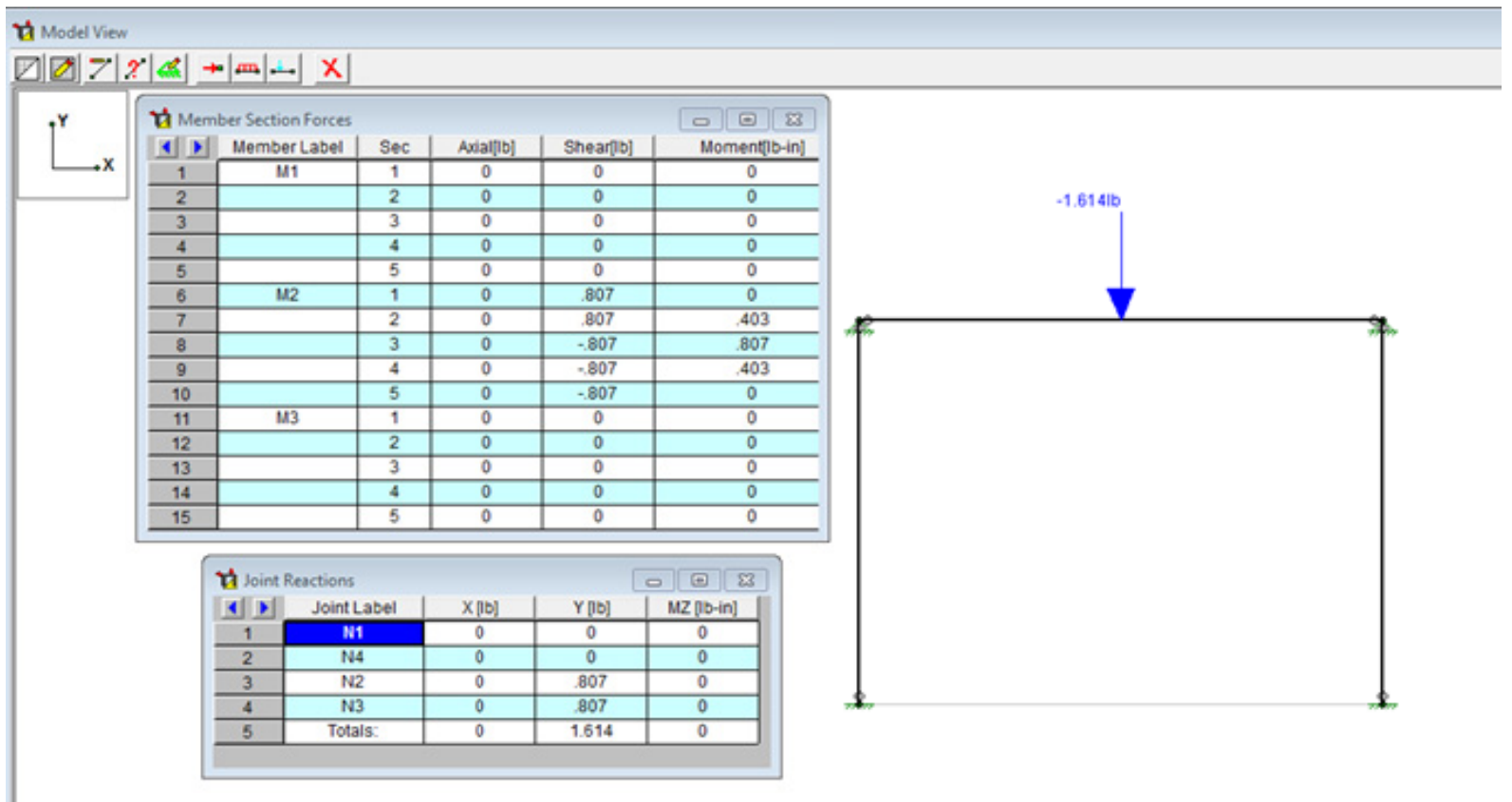

Fig. 6 Screenshot of the modeled portal frame using RISA-2D.

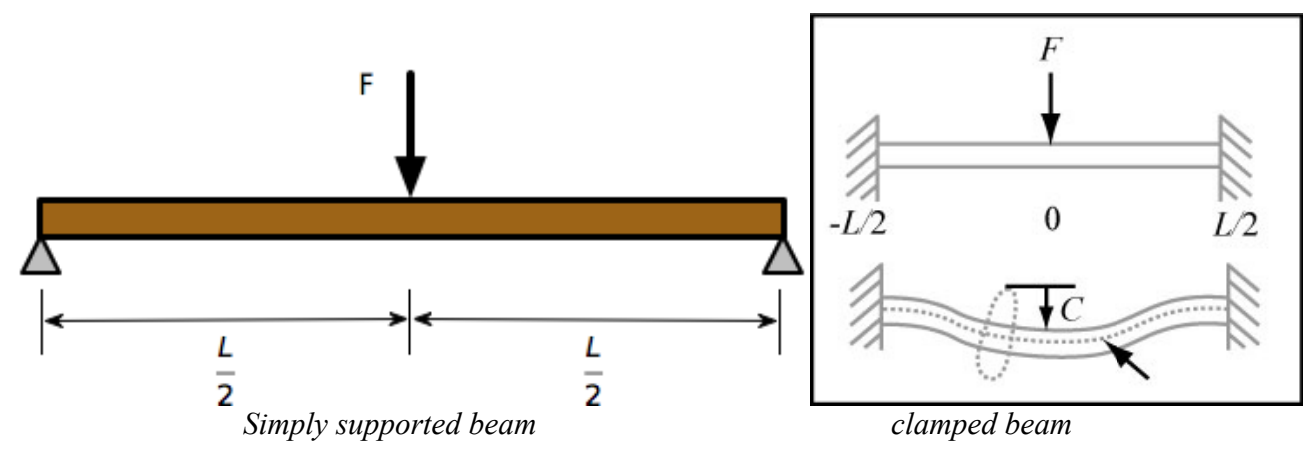

Fig. 7 Considered support conditions for theoretical calculations.

Table 1 Summary of experimental, numerical, and theoretical results.

\begin{tabular}{llll}
\hline$\delta_{\text {exp. }}[\mathrm{mm}](\mathrm{in})$ & $\delta_{\text {num. }}[\mathrm{mm}](\mathrm{in})$ & $\delta_{\text {theo }, \text { SS }}[\mathrm{mm}](\mathrm{in})$ & $\delta_{\text {theo.,cl }}[\mathrm{mm}](\mathrm{in})$ \\
\hline $5.59(0.220)$ & $8.15(0.321)$ & $10.49(0.413)$ & $2.62(0.103)$ \\
\hline
\end{tabular}

For the simply supported beam under a point load applied at its midspan, the maximum deflection ( $\delta_{\text {theo.,SS }}$ ) can be calculated using the following equation:

$$
\delta_{\text {theo.,SS }}=\frac{P l^{3}}{48 E I}
$$

in which, $I$ is the area moment of inertia of the cross section and can be calculated using $b t^{3} / 12$.

Similarly, the maximum deflection of a clamped beam $\left(\delta_{\text {theo.,cl }}\right)$ under a point load applied at its midspan, can be calculated using the following equation:

$$
\delta_{\text {theo.,cl }}=\frac{P l^{3}}{192 E I}
$$

\subsection{Comparison of Experimental, Numerical, and Theoretical Results}

The experimental result as well as the numerical and theoretical predictions of the midspan deflection of the beam are tabulated in Table 1 .

As expected, it can be seen that the experimental result lies between the extreme theoretical predictions 
of a simple support, on the one hand, and a clamped support, on the other. Moreover, the experimental result is found to be closer to the prediction of a clamped support, as the actual connection devised consisted of a pair of angles placed on the exterior as well as interior of the beam-to-column joints.

In addition, it is also observed that the numerical prediction of the midspan deflection lies between the predictions for simple and clamped support conditions. Despite the differences between the actual and numerical models due to limitations in modeling of the tested portal frame, the agreement between the experimental and numerical results is by and large satisfactory.

\section{Concluding Remarks}

In this educational research endeavor, a single-story, single-bay portal frame was designed, constructed, tested, numerically simulated, and theoretically analyzed. Through such an undertaking, the students were exposed to various engineering principles, issues, and processes. For instance, they were challenged with properly instrumenting the portal frame and also collecting reliable test data. This goal was achieved by guiding the students in both numerical modeling and theoretical analysis of the structure which served to bolster their simulation and computational skills. This endeavor is envisioned to be the first of its kind in a series of similar undertakings in the future for which additional structures, and loading and support conditions, will be devised and implemented. In addition to the fruitful educational purposes of such research activities, the final products of these endeavors will be effectively used for teaching, research, and recruitment purposes.

\section{Acknowledgments}

The authors would like to express their sincere and profound appreciation for the support and encouragement extended by Dr. S. K. Ramesh, Dean of the College of Engineering and Computer Science, and Dr. Nazaret Dermendjian, Chair of the Civil Engineering and Construction Management Department at California State University, Northridge.

\section{References}

[1] Felder, R. M., Felder, G. N., and Dietz, E. J. 1998. “A Longitudinal Study of Engineering Student Performance and Retention-Comparisons with Traditionally-Taught Students." J. of Engineering. Educ. 87 (41): 469-80.

[2] Dodge, R. E., Fisher, B. C., King, J. J., Kuehl, P. G., Matsuki, S., Mitchell, W. E., Dailey, J. F., and Boyajian, D. M. 2011. "Introducing the Structural Engineering Encounter Laboratory: A Physical Approach to Teaching Statics, Mechanics of Materials and Structural Analysis." World Transactions on Engineering and Technology Education 9 (2): 86-91.

[3] Davalos, J. F., and Qiao, P. 2003. "Effective Teaching and Learning of Composite Materials for Undergraduate Civil Engineering Students." In Proceedings of the 2003 American Society for Engineering Education Annual Conference \& Exposition, American Society for Engineering Education, $10 \mathrm{pp}$.

[4] Holzer, S. M., and Andruet, R. H. 1994. "A Multimedia Learning Environment for Statics." In Proc. ASCE Structures Congress XII, Atlanta, GA, 1Vol. 1, 308-14.

[5] Leonard, S., Mary, E. S., and Samuel, S. D. 1999. "Effects of Small-Group Learning on Undergraduates in Science, Mathematics, Engineering, and Technology: A Meta-analysis." Rev. of Educational Res. 69 (1): 21-51.

[6] Feisel, L. D., and Rosa, A. J. 2005. "The Role of the Laboratory in Undergraduate Engineering Education." Journal of Engineering Education (2005): Web. Aug 2016. 